\title{
Sun-Moon-Earth Interactions, External Factors for Earthquakes
}

\author{
M. Hagen"1, A. Azevedo² \\ ${ }^{1}$ Universidade Federal Fluminense, Instituto de Fisica, Niteroi, RJ, Brazil (retired); ${ }^{2}$ Faculdade de Ciências Aplicadas \\ da Unicamp-R. Pedro Zaccaria, São Paulo, Brazil
}

Correspondence to: M. Hagen, marhagen@indiana.edu; A. Azevedo, anibal.azevedo@fca.unicamp.br

Keywords: Sun, Moon, Earth, Solar Wind, Coronal Mass Ejections, Solar Cycles, Earthquakes

Received: May 16, 2017 Accepted: June 26, 2017 Published: June 29, 2017

Copyright $\odot 2017$ by authors and Scientific Research Publishing Inc.

This work is licensed under the Creative Commons Attribution International License (CC BY 4.0).

http://creativecommons.org/licenses/by/4.0/

\section{(c) (i) Open Access}

\section{ABSTRACT}

The aim of this paper is to continue analyzing the interactions in the three-body system made up of the Sun, the Moon, and the Earth. First, we review new details about Moon-Earth connections, with a special focus on mechanical forces. Following, we expand the study to consider the pair Sun-Earth, with calculations for electromagnetic forces. The objective in both cases is to know how mechanical and electromagnetic forces affect seismological events on Earth. Our calculations found that Solar Cycles have no direct interaction with earthquake variations. Instead, we established that there is an internal discrepancy for quakes below $35 \mathrm{~km}$ detected in some of the regions analyzed. The results indicate that geomagnetic variations must be studied next to understand their connections to earthquakes.

\section{INTRODUCTION}

In Influences of Solar Cycles on Earthquakes [1], Tavares and Azevedo explained a possible SunEarth influence through sun storms, which increase the solar wind speed and the flux of ionized particles. Most particles are reflected by the magnetopause and bow shock, but some enter the magnetosphere near the poles, creating the auroras. The high speeds of solar wind compress the earth's magnetosphere, changing its length from $10 \mathrm{R}_{\mathrm{E}}$ to $6 \mathrm{R}_{\mathrm{E}}$ in a short time. The magnetic pressure stores energy in the upper atmosphere, and apparently reaches some regions of the earth's crust in certain cases. The earth's crust and the oceans have different compositions and are affected differently. Any effects from the solar wind when coming through the atmosphere are also changed by the interactions of streams with the plasma jet in the higher atmosphere, and winds in the lower atmosphere. Our previous paper supposed that if the magnetosphere were quiet, the locations under pressure from high-speed winds would eventually reach a rupture point in the crust and possibly trigger earthquakes depending on the tectonics of each plate [1]. At that time, the authors worked with different tectonic plates worldwide. The references supporting their ideas 
are found in [2-8].

The Sun's diameter is one hundred and nine times that of the Earth, so it affects the planet as a whole, and the distance between the two bodies is 149.6 million $\mathrm{km}$. The gravitational forces vary with $1 / \mathrm{r}^{2}$, therefore, they are smaller than the electromagnetic forces. The Sun has two times the magnetic field of the Earth. The moon is 80 times smaller than Earth, but only $384,400 \mathrm{~km}$ away, so any variation in positioning or distance between them affects the gravitational forces that they exert on each other. Also, the moon does not have a magnetic field, but it does have a small paleomagnetic field. Now, we have enough knowledge to consider Moon-Earth as affected mechanically, and Sun-Earth as more efficiently affected magnetically. The inclusion of the Moon in this paper serves to update our recent article [9] about the interaction between the Moon and Earth. The second part of this paper will examine the influence of the Sun on the Earth with a wider view than in [1]. Our first conclusions for the gravitational force show the highest percentage of geohazard events took place when the Sun-Moon-Earth were aligned at $180^{\circ}$ with the Moon facing the Sun on its dayside magnetosphere (New or $1^{\text {st }}$ Quarter), [9]. The totality of data and calculations and papers for that paper can be evaluated in [10-13].

In this paper, we are working with Solar Cycle changes and possible influences on geohazards. In a future study, we extend the research to trace direct influences from CME and X-flares discrepancies data and disturbances in geomagnetic variations. Our results for earthquakes are from public catalogs: USGS, IRIS, $[14,15]$. Other data for Sunspots, Coronal Mass Ejections, Solar flares, Solar Storms, Moon data connections, and Moon catalogs are in [16-26].

Sun-Earth has elusive interconnections if one works with statistical data, which can easily be mistaken or misinterpreted. A solar cycle is defined by the patterns in the amount of magnetic flux from the Sun's surface, and these patterns extend across approximately eleven years. It is sometimes called a sunspots cycle with two peaks, a minimum period with small and few sunspots and a maximum period with large and visible sunspots almost all the time. Sunspots locations are characterized by strong magnetic fields. In this part of our research, we consider the last two solar cycles, cycle 23 (1996-2008) and cycle 24, (2008unclosed). Cycle 23 peaked in 2000, and cycle 24 did so in 2014. The development of those cycles during their minimum levels and peaks is compared to earthquake activity in the same period. The data for earthquakes are divided by activity, magnitude, depths, and coordinates.

The coordinates serve to demarcate areas with the lowest or highest seismic activity. However, the growth found at greater depths does not coincide with the solar maxima; in many cases, this activity occurred during the minima. These results lead us to conclude that earthquakes are not linked to the development of solar cycles, but instead internal disparities caused by disturbances in the geomagnetic variations may be affected by other solar events such as X flares or Coronal Mass Ejection. Also, not all of the earth's crust presents deep earthquakes, and depths vary for each zone examined. What this means is that the crust is not homogeneous, and thus any modification factor results from a combination of external geomagnetic disturbances and local internal components which seem to be associated with different seismological growths for each region.

\section{VARIATIONS IN THE MOON'S ATTRACTION ON THE EARTH}

In a previous article calculating the gravitational force of the Moon-Earth we found a wave with large period and small amplitude. The peaks of this force correspond with the New or Full moon (Spring tides) and the minimum aligns with the $1^{\text {st }}$ or $3^{\text {rd }}$ Quarter moon (neap tides). The new or full moon phases created the highest tides observed in the oceans. The waves had the greatest effect in subduction zones, as found in our last paper. This oscillation movement happens at the Perigee, the nearest position the Moon reaches in its elliptical orbit around Earth. The waves do not affect all regions in the same way since plate tectonics are different due to geometry, material, structure, and composition. The force between the Moon and Earth is

$$
F=G m M / r^{2}
$$

Here, $m=$ moon mass $=7.34 \times 10^{22} \mathrm{~kg}, M=$ earth mass $=5.97 \times 10^{24} \mathrm{~kg}, G=$ gravitational constant $=$ 
$6.67 \times 10^{-11} \mathrm{~m}^{3} \cdot \mathrm{kg}^{-1} \cdot \mathrm{s}^{-2}$.

The only variable is $r$, or the distance between the Moon and Earth at Perigee, and this distance varies by approximately $3.5 \%$ each year [17-20]. The oscillatory force is small with a period of $6-7$ months. In the period 1996-2008, this interval repeated as Figure 1 shows. During Solar Cycle 23, this variation completed 11 full periods. We expect solar cycle 24, which started in 2008, to end in one and a half years. Therefore it is probable that the next cycle, 25, will start at the middle or end of 2019.

In subduction zones, water may reach inner parts of the earth beneath the crust. During the highest tides, the water spreads more quickly below land in subduction zones [9]. Those places accumulate energy and stress, and the water adds strain and pushes toward the earth's center. The water running beneath the continent allows different processes to occur, such as the serpentinization of rocks and the creation of convection currents that blow hot water to the cold surface. Therefore, the oceanic currents affected by tides play a robust role in the accumulation of strain and stress in such regions. The interval before an earthquake occurs depends on connections with tides to a greater or lesser degree. The continuous displacement of waves weakens the rocks and shifts their positions, triggering tremors. The cavities below the plates fill with water from the ocean's movement and the water is heated by the temperature of the earth. Large earthquakes involve longer processes and depend on each region's particular durability and resistance before a disruption or collapse occurs. A megathrust earthquake may take many years to form. Even though the syzygy tides happened during both New and Full Moon periods, our calculations demonstrated that seismic events occurred at or close to the New Moon.

If tides are connected to earthquakes, why do we not see the triggering of giant quakes in all regions with high tides? The Bay of Fundy, Canada, features the highest tides in the world, but there are no records of outsized earthquakes. The explanation links events such as tides and ocean waves to the geology and

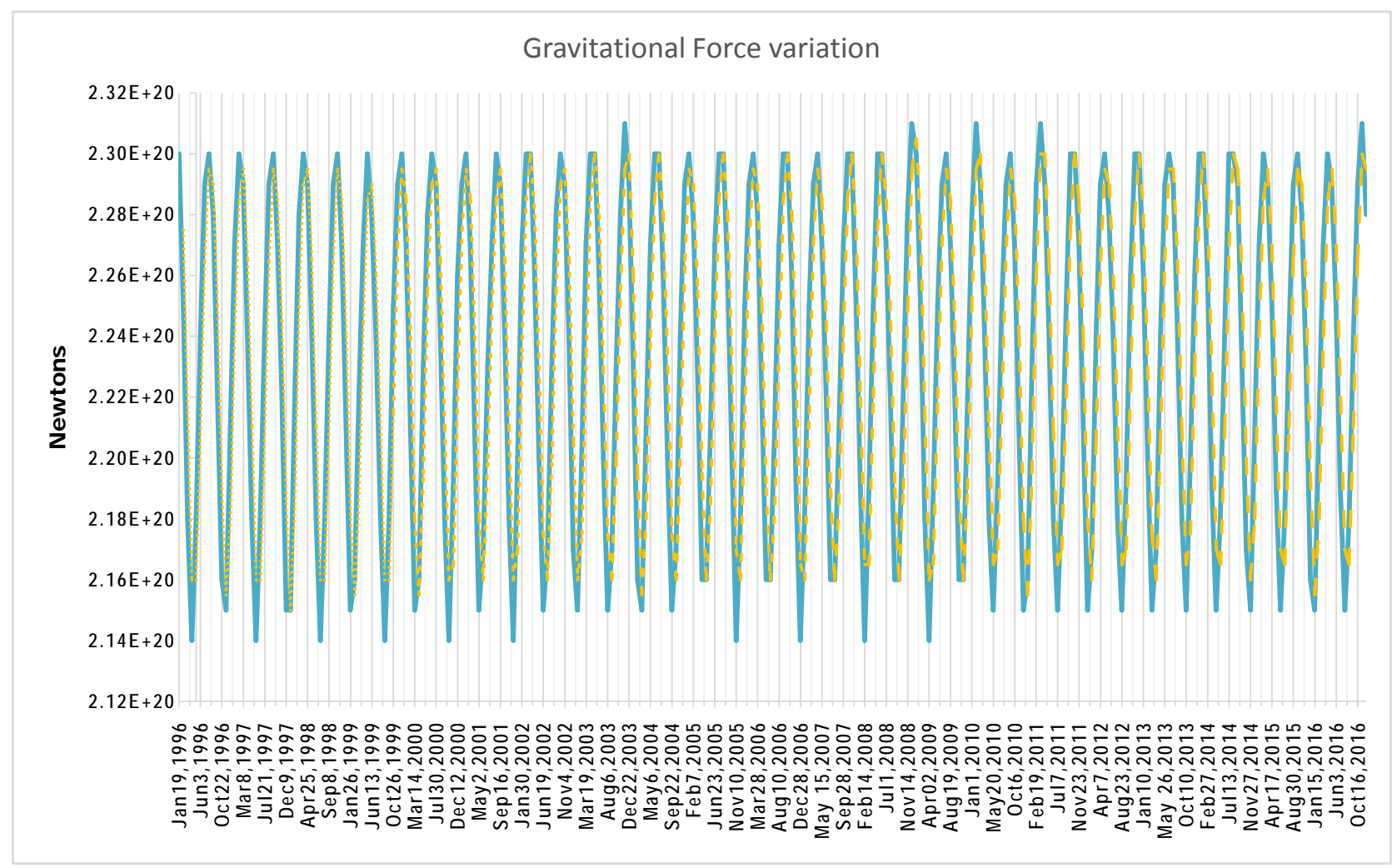

Figure 1. Gravitational Force Variation 1996-2016. Maximum force was consistently reached during the New or Full Moon. The minimum power was in the First or Third quarter. These calculations based on the data files for the Perigee and Apogee positions [17]. 
tectonics of each region. Subduction zones seem to make it easier to trigger earthquakes compared to other seafloor formations connected to Canada's mainland. Therefore, the Pacific floor structure is essential to understanding how oceanic waves interact in the subduction zones. There is a possibility that the smaller earthquakes as defined in our earlier paper $M \geq 4.5$ increased in number in subduction locations during the New or Full Moon, and it is further possible that the same phases can enhance the number of events with smaller magnitudes. Several foreshocks are created by the higher tides and the increased intensity of the waves.

\subsection{Lunar Gravitational Oscillations and Connections with Quakes}

We obtained a gravitational force variant created when the moon reaches the Perigee. Solar cycle 23 (1996-2008) spanned 11 moon cycles, or the time necessary to describe a whole period, [17-19]. Figure 1 shows the maximum value for oscillation between Moon-Earth as $2.32 \times 10^{20} \mathrm{~N}$. At these points, the moon phase was always a new or full moon, when the tides were highest. The minimum value is $2.13 \times 10^{20} \mathrm{~N}$. The amplitude is small but the period is around 6 months.

The complete Cycle 23 included 11 moon cycles. If Cycle 24 follows the same pattern, it will conclude at the middle or end of 2019. The mathematical results and Figure 1 suggest the possibility that mega and large earthquakes happen more frequently at New or Full moons when the tides are higher in subduction locations along shorelines. Although we established the gravitational force for Moon-Earth, it is impossible to make the same calculation for a possible electromagnetic force between the two bodies. In fact, Moon-Earth is not supposed to have electromagnetic links, since the Moon does not have a magnetic field, but a small paleomagnetic variation of around $2.5 \mathrm{nT}$.

\subsection{Moon-Earth Connections Results}

Complementary results for Moon-Earth [9], display a gravitational pulsation when the moon is located at the Perigee. The peak of the force is reached during the New (mostly) and Full Moon. The minimum is in the First or Third Quarter. The greatest effects shown in the figure occur at the highest tides, which affect the subduction zones at the shorelines. The largest earthquakes happened during those moon phases. To reach this conclusion we constructed two lists, first with all mega-quakes since the first records in 869 through 2015. These data indicated that the shakes were distributed between the New Moon (38\%), Full (21\%), $1^{\text {st }}$ Quarter (23\%) and $3^{\text {rd }}$ Quarter (18\%) as shown in Figure 2. The position of New Moon or $1^{\text {st }}$ Quarter means the Moon is closest to the Sun. The Moon position has a significant impact on the gravitational variation and the enhancement of quakes, as shown in Appendix A and Figure 2.

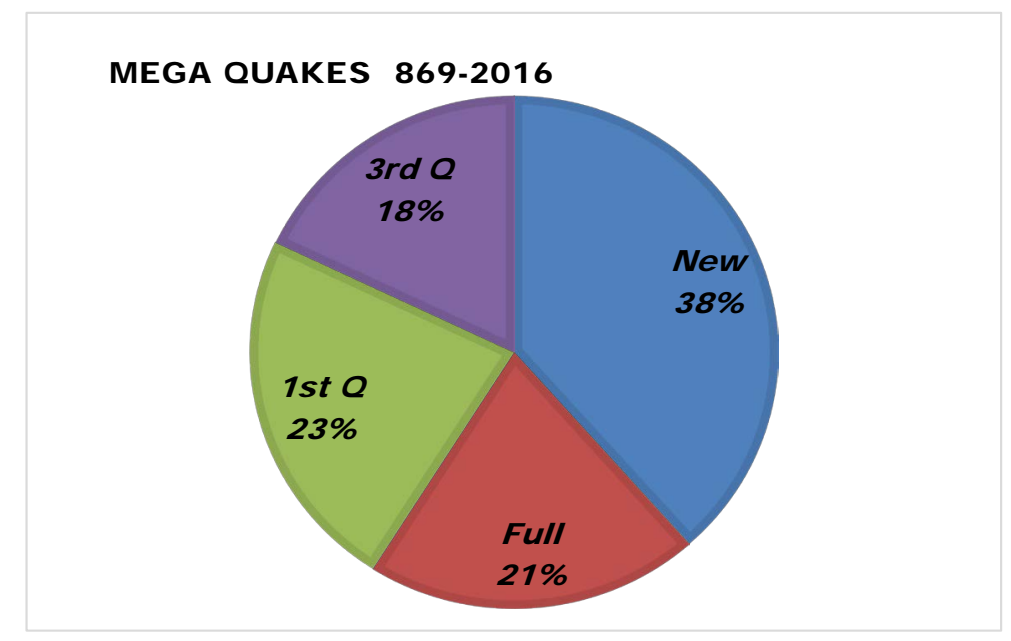

Figure 2. Mega quakes magnitude $M \geq 8.5$ correspondences with moon phases for period 869-2016. 
Appendix B displays results for large earthquakes $M \geq 8$ that occurred during the period 1950-2016. The changes for the Moon phases are similar to Appendix A: the majority happened at the New Moon (35\%), Full (22\%), $1^{\text {st }}$ Quarter $(23 \%)$ and, $3^{\text {rd }}$ Quarter (20\%). Figure 3 shows the distribution of quakes between moon phases.

The last results are to describe the locations and the probability of a massive earthquake surge. The Northern and Southern Pacific had 78\% of occurrences, the Indian Ocean showed $14 \%$, and $8 \%$ occurred in other regions. This $8 \%$ includes: $7 \%$ intraplate quakes in the Northern Hemisphere, and $1 \%$ in the North Atlantic. There was no occurrence of intraplate activity in the Southern Hemisphere. Those results drove the following conclusions:

a) The next Solar Cycle, 25, will start in 2019, most probably in the middle or at the end of the year. In Figure 1 the Cycle 23 covered 11 moon cycles, the Cycle 24 possibly will end in 2019 based on the same assumptions.

b) Biggest earthquakes (over a period of one century) occurred at the New Moon (Figure 3).

c) The largest earthquakes occurred in subduction zones [9]. They comprised $M \geq 8$ as confirmed by historical records. This corresponds with data in Figure 4 and Appendix B.

d) Most of the major events occurred on the Pacific coast. See Figure 4 and Appendix B.

e) Significant intraplate events comprise $7 \%$ of the total and these events only occurred in the Northern Hemisphere (Figure 4).

\section{SOLAR CONNECTIONS TO THE EARTH}

\subsection{Interactions Sun-Earth}

The sun's magnetic field is approximately twice as strong as that of Earth. Solar wind conditions can create geomagnetic storms lasting for a period of hours, characterized by periods of high-speed solar winds, and most importantly, a southerly solar wind magnetic field (which is the opposite direction of Earth's field). This condition is efficient for transferring energy from the solar wind into Earth's magnetosphere. Solar flares pass through the magnetosphere and directly affect the ionosphere. The dynamic pressure from the solar wind on Earth is expressed as:

$$
P=1.672 \times 10^{-6} \times n \times v^{2}
$$

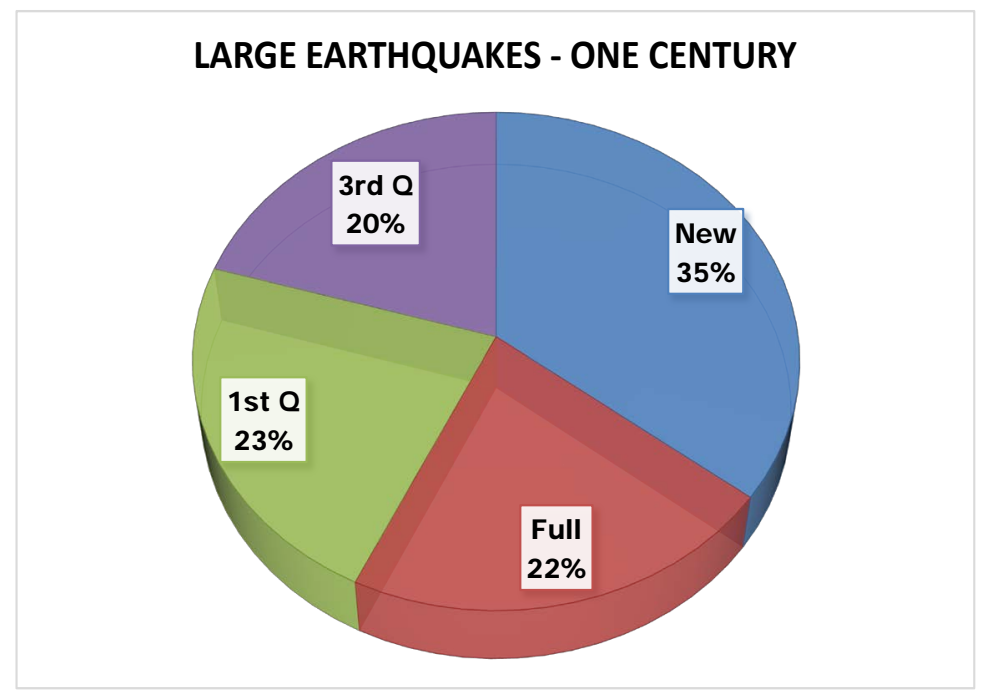

Figure 3. Locations of large earthquakes worldwide for the period 1900-2016, $M>8.0$. The results are similar to the mega quakes during the period 869-2016. 


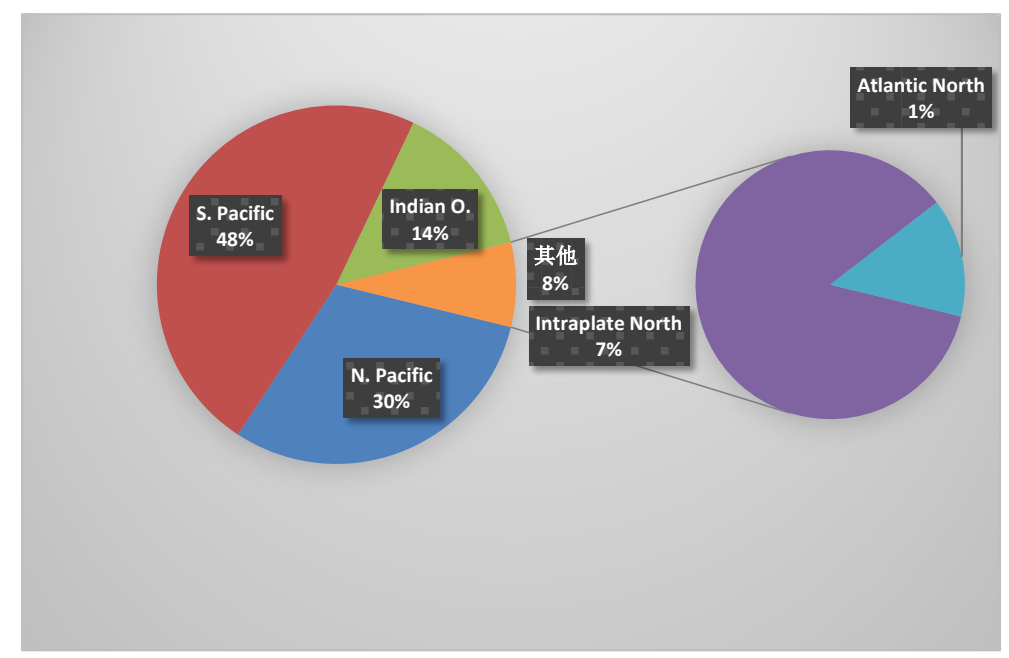

Figure 4. Global distribution of events by region. $78 \%$ occurred in the Pacific, $14 \%$ in the Indian Ocean, and $8 \%$ in other locations. This indicates that $92 \%$ of giant earthquakes occur in ocean subduction zones.

$P=$ Nano-pascals, $n=$ particles $/ \mathrm{cm}^{3}$ and, $v=\mathrm{km} / \mathrm{s}$, both $n$ and $v$ varies depending of the intensity of Solar Storms [1].

The dynamic pressure is much larger than the thermal pressure or magnetic pressure from solar wind. Within the magnetosphere the magnetic pressure of the Earth's internal field dominates. This pressure (2) acts on the magnetopause (dayside) at the boundary and the variation of solar wind changes the dynamic pressure in the region. The solar wind (day side) pressure pushes the magnetosphere, varying in a large range of length that is usually $10 \mathrm{R}_{\mathrm{E}}$ but can drop as low as $6 \mathrm{R}_{\mathrm{E}}$ after a major solar storm $\left(\mathrm{R}_{\mathrm{E}}=6370\right.$ $\mathrm{km})$. The earth's magnetic field on the night side can be stretched by the solar wind to hundreds of Earth radii, beyond the orbit of the moon at $60 \mathrm{R}_{\mathrm{E}}$. The electromagnetic disturbances strain the Earth system and depend on the density of particles charging the poles and going to the lower levels of the magnetosphere, including the stratosphere, ionosphere and Van Allen belts [8].

The Sun-Earth connections are primarily electromagnetic and caused by the solar disruptions. Sun-Earth-Moon interaction is highly dependent on electromagnetic waves. The solar cycle or solar magnetic activity cycle follows an 11-year period. Solar activity describes changes in the levels of solar radiation and ejection of solar material. We first searched for any connections between solar cycles and natural hazard events during two solar cycles, labeled cycle 23 (period 1996-2008) and partial cycle 24 (2008-unclosed). Since earthquake distribution around the globe varies by region, we divided the world into distinct locations by coordinates. In addition, the maximum depth of the epicenters was considered by each location. The results pointed out that the enhancement of events happens more frequently in the deeper lithosphere than in the crust.

\subsection{Geomagnetic Storms}

The earth's main geomagnetic field varies slowly and originates within the Earth itself. There are rapid deviations in periods ranging from seconds to days, produced by processes in the Earth and the ionosphere. The sequences of phenomena that give rise to geomagnetic disturbances originate on the Sun. We constructed a model for the transient magnetosphere response to Solar wind pressure variations. The effect of those disturbances in the signatures of the pressure-pulse driven magnetopause motion includes a bipolar magnetic field signature of magnetosphere orientations. Overall, any connection between the Sun and Earth must be relate to geomagnetic variations affected by full solar storms releasing high energy par- 
ticles and radiation to the Earth [8]. Geomagnetic storms must affect the Earth and its internal magnetic field, but are not directly linked with sunspots. Therefore, further analysis is necessary to establish the real significance of these disturbances on the Earth.

\section{QUAKES VARIATION DURING SOLAR CYCLES}

There are too many variables in our study to reach a definite conclusion now about the connection between solar cycles and earthquake enhancement. We divided the world into several regions according to the seismological activity record for each of them. We divided records for each region according to different depths where quakes triggered. The depth levels are as follows: Level 1, 0 - $35 \mathrm{~km}$; Level 2, $35-70 \mathrm{~km}$; Level 3, 70 - $300 \mathrm{~km}$; Level 4, $300-500 \mathrm{~km}$; and Level 5, $\geq 500 \mathrm{~km}$. Some of the areas defined below did not show seismological activity at lower depths. Coordinates and number of layers by depth demarcate the locations below,

Area A: $70.14 \mathrm{~N},-54.16 \mathrm{~S},-65.04 \mathrm{E}, 139,57 \mathrm{~W}$, matches the East Pacific area (Americas). This region corresponds to the highest geohazard events recorded. This region is also known as the Ring of Fire.

Area B: $79.56 \mathrm{~N},-30.75 \mathrm{~S}, 136.5 \mathrm{E},-18.03 \mathrm{~W}$, West Pacific (Asia), Africa, and Europe.

Area C: $10.83 \mathrm{~N},-69.75 \mathrm{~S}, 17.75 \mathrm{E},-71.89 \mathrm{~W}$, South Atlantic Ocean and South America.

Area D: $71.52 \mathrm{~N}, 1.76 \mathrm{~S},-20.12 \mathrm{E},-160.06 \mathrm{~N}$, Canada, North America, North Atlantic, Mexico, Central America.

Area E: $73.23 \mathrm{~N}, 2.81 \mathrm{~S}, 43.42 \mathrm{E},-81.04 \mathrm{~W}$, Europe, North Africa, and North Atlantic.

Area F: $83.91 \mathrm{~N},-64.47 \mathrm{~S}, 7.38 \mathrm{E},-39.02 \mathrm{~W}$, Arctic Sea, Greenland, Atlantic.

Area G: $43.083 \mathrm{~N},-68.01 \mathrm{~S}, 152.40 \mathrm{E},-13.05 \mathrm{~W}$, South Atlantic, South Pacific, South Indian Ocean.

Area $\mathrm{H}-52.08 \mathrm{~N},-77.24 \mathrm{~S},-39.90 \mathrm{E},-169.98 \mathrm{~W}$, Southern Ocean.

Zones $\mathrm{A}, \mathrm{B}$, and $\mathrm{C}$ had events in all five depth layers. Regions $\mathrm{D}, \mathrm{E}$, and $\mathrm{F}$ had three active layers $(0$ $35 \mathrm{~km}, 35-70 \mathrm{~km}$ and, $70-300 \mathrm{~km})$. Areas G and H only had activity at level $1(0-35 \mathrm{~km})$, and the magnitude of the earthquakes at this level was up to M5. The depth at which most earthquakes happen is $0-35$ $\mathrm{km}$, therefore, we separated this depth in a particular plot to show all location variations at this level. It was also necessary to consider only magnitudes M5 or above at shallower levels. Our first plot is a set of all regions and earthquakes with magnitudes M5 or above at the 0 - $35 \mathrm{~km}$ depth (Figure 5).

Table 1 and Table 2 define each region. The Tables give the coordinates and nomenclature of each area analyzed.

Table 1. Coordinates for areas A, B, C, D, and E to examine quakes with different magnitudes and depths.

\begin{tabular}{cc}
\hline Areas & Coordinates \\
\hline A: West Pacific (AMERICAS) area & $70.14 \mathrm{~N}, 54.16 \mathrm{~S}, .65 .04 \mathrm{E}, 139.57 \mathrm{~W}$ \\
B: East Pacific(Asia), Europe, Africa & $79.56 \mathrm{~N}, 30.75 \mathrm{~S}, 136.05 \mathrm{E}, 18.03 \mathrm{~W}$ \\
C: South Atlantic Ocean, South America & $10.83 \mathrm{~N}, 69.78 \mathrm{~S}, 17.75 \mathrm{E}, 71.89 \mathrm{~W}$ \\
D: Canada, N. America, N. Atlantic, Mexico, Central America & $71.52 \mathrm{~N}, 1.76 \mathrm{~S}, .20 .12 \mathrm{E}, 160.06 \mathrm{~W}$ \\
E: Europe, North Africa, North Atlantic & $73.23 \mathrm{~N}, 2.81 \mathrm{~S}, 43.42 \mathrm{E}, 81.04 \mathrm{~W}$ \\
\hline
\end{tabular}

Table 2. Coordinates for areas F, G, and $H$ to examine quakes with different magnitudes and depths.

\begin{tabular}{cc}
\hline Areas & Coordinates \\
\hline F: Arctic Sea, Greenland, Atlantic & $83.91 \mathrm{~N}, 64.47 \mathrm{~S}, 7.38 \mathrm{E}, 39.02 \mathrm{~W}$ \\
G: South Atlantic, South Pacific, South Indian Ocean & $152.40 \mathrm{E}, 13.54 \mathrm{~W}, 43.83 \mathrm{~N}, 68.01 \mathrm{~S}$ \\
H: Southern Ocean & $-77.24 \mathrm{~S}, 52.05 \mathrm{~N}, 39.90 \mathrm{E}, 169.98 \mathrm{~W}$ \\
\hline
\end{tabular}




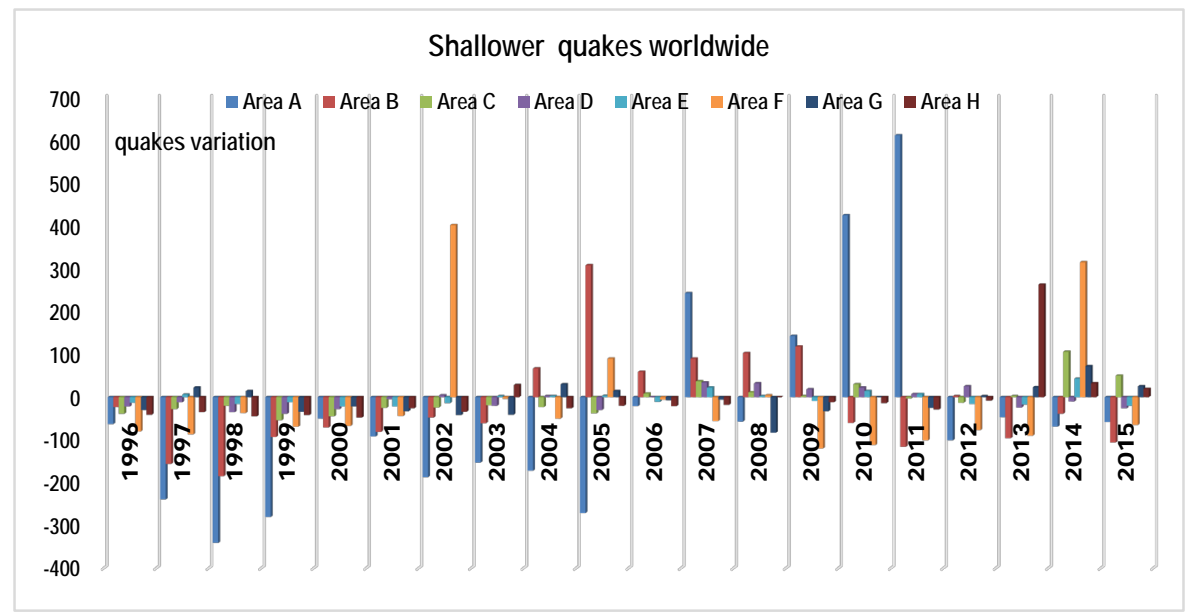

Figure 5. Variation of average shallower earthquakes $(0-35 \mathrm{~km})$ during two solar cycles. Area A (East Pacific) had positive peaks 2009-2011. Observe the highest peaks in area $\mathrm{F}(2002,2005,2014)$, area B (2004-2009), area C (2014) and area $H$ (2013). Only three sectors increased at the last solar maxima in 2014, areas C, F and G. Negative peaks observed for all sites until 2003.

\subsection{Method Used}

The method used to determine if earthquakes increased or not over each cycle and if changes followed the maxima of each cycle, we did the following:

First, we separated the world into regions A-H defined above (eight regions). We examined activity by depth in those regions and defined depths ranges by levels $1-5$. We tracked activity during a period defined by solar cycles; we searched for a possible increase of geohazard events in all of Cycle 23 (1996-2008), and Cycle 24 through 2015 (2008-2015, cycle 24 is incomplete) for a total of 19 years of calculations.

We recorded all earthquakes for each year according to depth and divided them by level. For the shallower levels, we considered magnitudes $M \geq 5$. Therefore, we constructed a table of $N$ values for each year, all of them added and the total divided by 19; this number is the average number of events per year.

\subsection{Construction of Plots}

The data set comprises earthquakes recorded during the period 1996-2015. The sum of data values were $y_{1}=$ data recorded in the first year level $n(0-35 \mathrm{~km}, \geq 500 \mathrm{~km})$ in the region $\mathrm{X}(\mathrm{A}, \mathrm{B}, \mathrm{C}, \mathrm{D}, \mathrm{E}, \mathrm{F}, \mathrm{G}$, $\mathrm{H})$

$$
\sum_{n 0}^{n n} Y_{n}=y_{n 0}+y_{n 1}+\cdots+y_{n n}
$$

where $n=1996 \ldots 2015$, and $n$ ' is 19 years.

The mean is defined as

$$
\begin{gathered}
\text { Mean }=A=\frac{\sum_{n 0}^{n n} Y_{n}}{19} \\
\text { Data value-mean }=Y_{n}^{\prime}
\end{gathered}
$$

If $Y_{n}^{\prime}>A$, the number will be positive during that year and it means the number of earthquakes exceeds the average.

On the other hand, if $Y_{n}^{\prime}<A$ the number will be negative during that year, indicating that the number of earthquakes that year was below the average. The next sections explain each region and discuss the earthquakes that occurred. 


\section{RESULTS AND DISCUSSION}

\subsection{The Shallower Earthquakes}

Our first plot displays the more superficial earthquake distribution in eight world regions. Figure 5 shows the earthquakes recorded in the period 1996-2008 during approximately two solar cycles. During Cycle 23 there was no enhancement of events in any location. Area A (East Pacific area) had an enhancement during 2009-2011, but for most of the period analyzed there was no significant increase in this region. For location B (Europe, Asia and Africa), an increase occurred 2005-2009, and in area C (South Atlantic and South America) events increased in 2014 during the solar maxima of Cycle 24. For area F (Alaska, Greenland and Artic Sea), a surge appeared in 2002 and 2014. Finally in the Southern Ocean (area $\mathrm{H}$ ), we saw significant activity in 2013. The Southern Ocean only has shallow earthquakes, so a sudden increase in shallow events would indicate sources other than natural ones. In 2013 especially there occurred a large enhancement from unexplained sources. Shallower quakes are more difficult to trace to a specific cause of growth; today there are several anthropogenic experiments in regions that are supposed to be isolated, so we are unsure of the credibility of certain data. The continual enhancement of seismic activity over multiple years, or a sudden increase in locations known to have only a small number of tremors has more value in this examination. Our results for shallower earthquakes do not indicate a clear dependence on events such as the Solar maxima that occurred in 2000 or 2014.

Regions with shallower seismic activity such as F, G and H showed an increase in activity at depths of $10-20 \mathrm{~km}$ around the Solar Maxima of Cycle 24. The extreme coordinates of the Northern Hemisphere in Alaska, Greenland and Arctic Sea (area F), and the extremes of the Southern Hemisphere in South Atlantic, South Pacific and South Indian Ocean (area G) presented an increase of events in 2014 (the solar maxima of Cycle 24). The Southern Ocean showed a maxima of tremors in 2013 not connected with the Solar maxima.

\subsection{Pacific Area}

In this area, we analyzed four levels separately, $35-70 \mathrm{~km}, 70-300 \mathrm{~km}, 300-500 \mathrm{~km}$, and >500 km. This region is one of the most active worldwide, Figure 6 . The first surprise observation is a slow increase in events after 2005 in the level $35-70 \mathrm{~km}$, with some periods of decreasing events. The maximum enhancement was in the years 2008, 2010, and 2011. The declines occurred in 2009 and 2013. This outcome seems to indicate an internal cause. The next stratum, $70-300 \mathrm{~km}$, displayed different patterns during the period observed. At this level, the events enhanced most from 2004 to 2008, with a maximum in 2008. For the depth $300-500 \mathrm{~km}$, the increase years are 2004-2008 at a lower pace, and for $>500 \mathrm{~km}$ they are 2004 and 2008. There are two important conclusions; one is there is a surge of seismological events below the crust and in the levels $70-300 \mathrm{~km}$ and $300-500 \mathrm{~km}$ that fall in the same years. There is also no evidence they happened during any solar maxima. The occurrences might be associated with unknown internal parameters.

\subsection{Europe, Asia, and Africa}

This location had significant modifications after 2003, with positive seismological variations occurring at depths of $35-70 \mathrm{~km}$ during 2005-2010 and in 2014, Figure 7. In the layer $70-300 \mathrm{~km}$, variations occurred in 2004, 2005, 2006-2008, 2014, and 2015. Surprisingly, there was no positive variation for the depth $300-500 \mathrm{~km}$. At depths $>500 \mathrm{~km}$ variations appear in 2006 and 2015 with a smooth increase. These outcomes indicate the stratum $70-300 \mathrm{~km}$ as the most active, and the last ten years are perhaps connected with internal disturbances below the crust. Again, 2014 indicates an increase at two depths, $35-70 \mathrm{~km}$ and $70-300 \mathrm{~km}$. There were no decreases observed after 2014 at any level.

\subsection{South Atlantic, South America.}

This region shows unique behavior for the three levels analyzed. At levels $300-500 \mathrm{~km}$, no events 


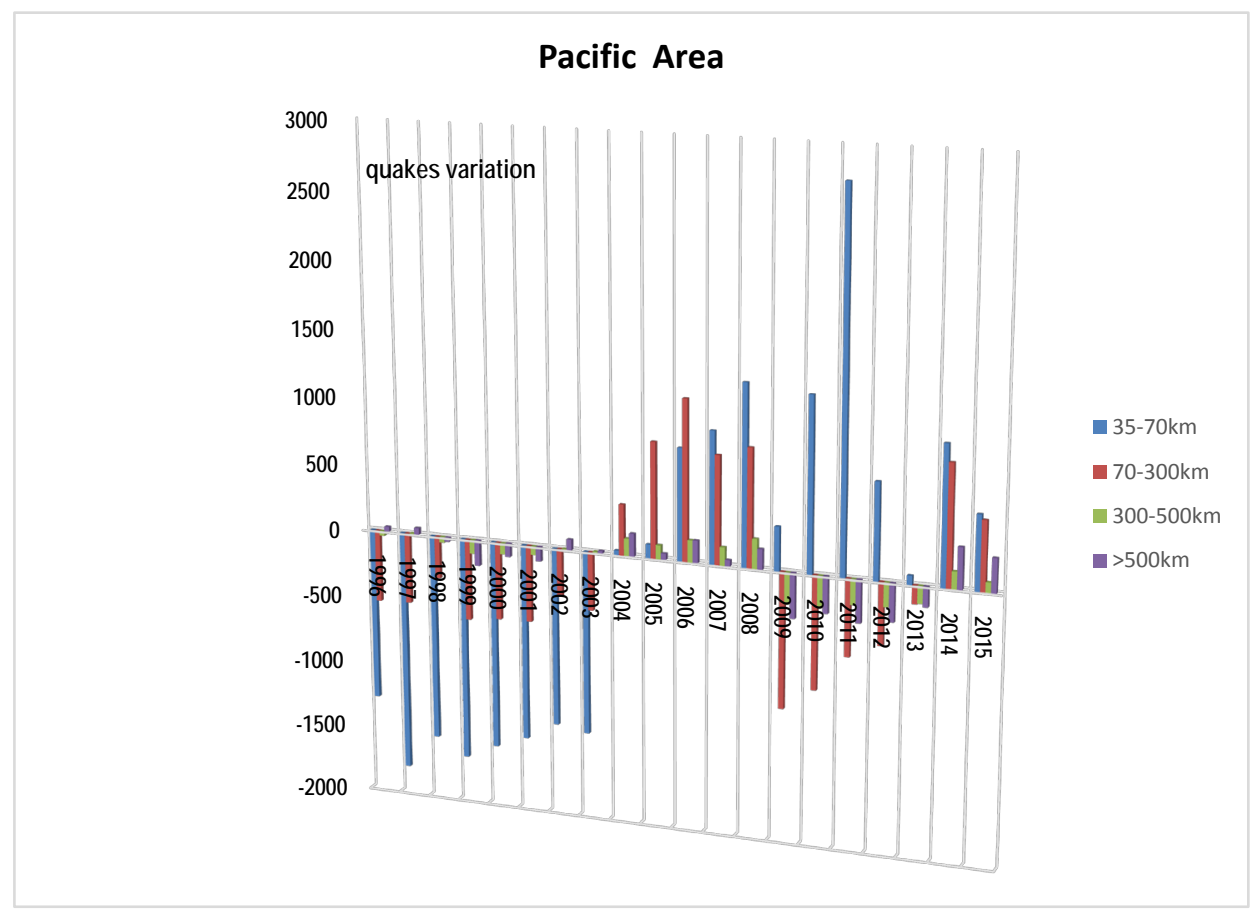

Figure 6. Quake variation in the East Pacific area, by depth. We noted that the depths $35-70 \mathrm{~km}$ and $70-300 \mathrm{~km}$ have continuous enhancements during certain years. The $35-70 \mathrm{~km}$ depth increased 2005-2015 with a maximum in 2011. The depth 70 - $300 \mathrm{~km}$ enhanced 2004-2008 and 2014-2015. The highest increases happened after 2006 at depths of $35-70 \mathrm{~km}$ and at $70-300 \mathrm{~km}$ during the period 2004-2008.

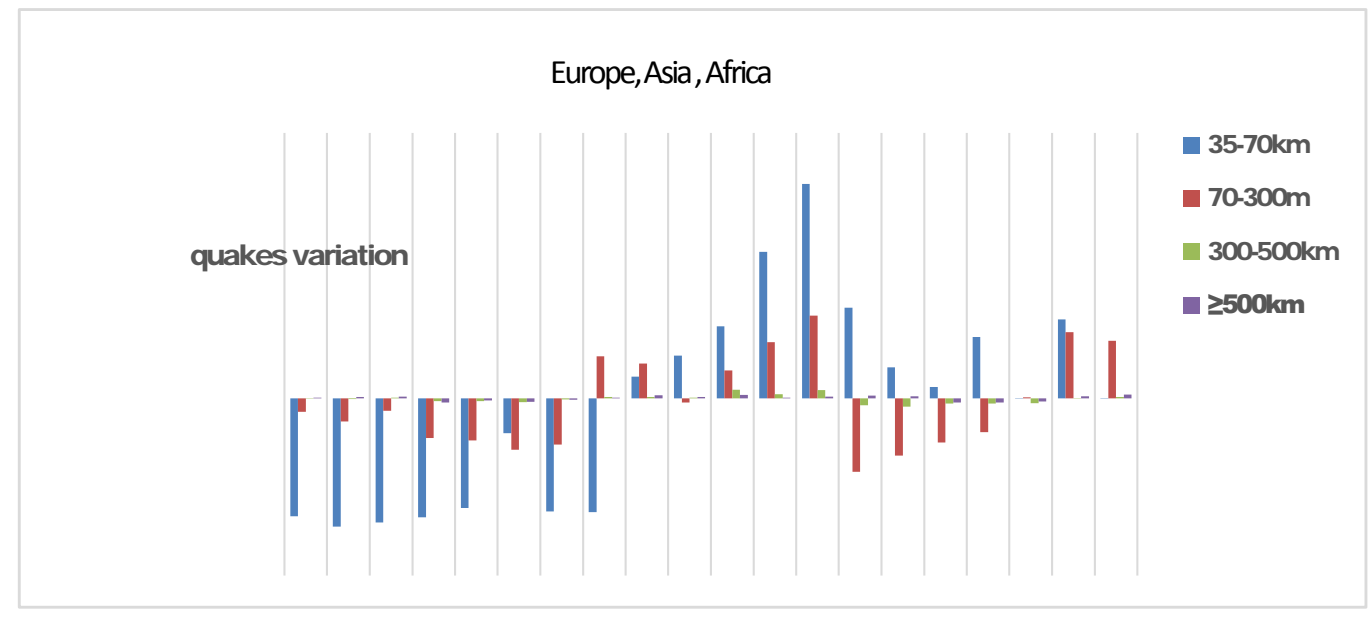

Figure 7. Quake variation by depth for Asia (West Pacific), Europe, Africa. The data showed an increase at depths of $35-70 \mathrm{~km}$ for the years 2004-2012 and again in 2014. In area B, growth at the depth 70 - $300 \mathrm{~km}$ only happened in 2003 and 2015.

were recorded, Figure 8. At $>500 \mathrm{~km}$ the variation was always negative. The only levels that had an increase in events were $35-70 \mathrm{~km}$ in 2006, 2007, and 2015, and $70-300 \mathrm{~km}$ during the period 2005-2008. The level $35-70 \mathrm{~km}$ showed a slight growth in 2006 and 2007, and at the $>500 \mathrm{~km}$ level, no enhancement was found during the entire cycles studied. 


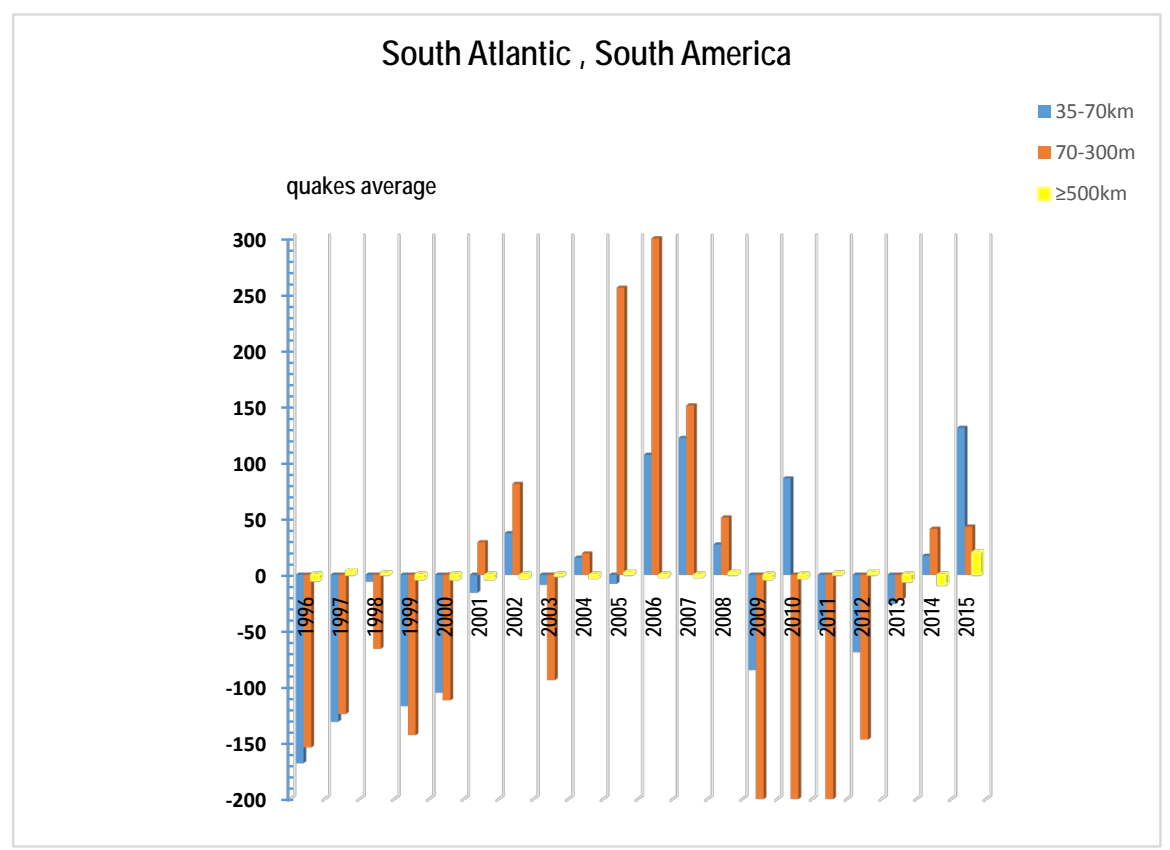

Figure 8. This figure shows the enhancement of quakes in Area C (South Atlantic, South America) at depths of $35-70 \mathrm{~km}$ in 2002, 2006-2008, 2010, 2015, and at depths of $70-300 \mathrm{~km}$, in 2004, 2005, 2008 and 2014. There are seldom events in the depth $300-500 \mathrm{~km}$. There is no significant increase in earthquakes $\geq 500 \mathrm{~km}$.

\subsection{Canada, North America, Mexico and Central America}

In this location, seismic events increased in 2008 and during 2011 to 2015 . The layers where these changes took place were $35-70 \mathrm{~km}$ and $70-300 \mathrm{~km}$, Figure 9. The shallowest strata show a faster growth during the 2011-2015 interval, and the deeper layer grew more between 2005-2008. It is important to note that in the period of the first cycle, Cycle 23, there was no increase in the number of earthquakes until 2005. Since that year, the $70-300 \mathrm{~km}$ depth rose rapidly, followed by the shallowest $35-70 \mathrm{~km}$ level.

\subsection{Europe, North Atlantic, North Africa}

Area E comprises Europe, the North Atlantic, and North Africa. The depths where earthquakes occurred are $35-70 \mathrm{~km}$ and $70-300 \mathrm{~km}$, Figure 10. In these regions, the tremors grew abruptly between 2006-2008 and after 2012-2016. There is always a discrepancy between the growth of earthquakes at a given depth. In the layer between $35-70 \mathrm{~km}$, the tremors grew 2006-2008 and then 2012-2015. At the other depths, this happens to a lesser degree during 2006-2008 and is less evident in 2014-2015. We can say that the upper layer has a faster and stronger growth than the lower one, creating a quasi-periodicity between the two levels.

\subsection{Alaska, Greenland, Arctic Sea}

The number of events in this region is few, or at least the detection of them is not as good as in other locations addressed in this study, Figure 11. In any case, we can risk a guess that we detected a positive growth of tremors in cycle 23 for the depth $35-70 \mathrm{~km}$ in the years 1997, 2004, 2005, and 2008, and that in cycle 24 this depth did not have any alteration. At the depth 70 - $300 \mathrm{~km}$ the opposite happened: the period where the most earthquakes occurred at this depth was between 2009 and 2014 in cycle 24, showing a desynchronization between the two depths. Cycle 23 corresponded to growth at $35-70 \mathrm{~km}$, and Cycle 24 showed growth at $70-300 \mathrm{~km}$. 


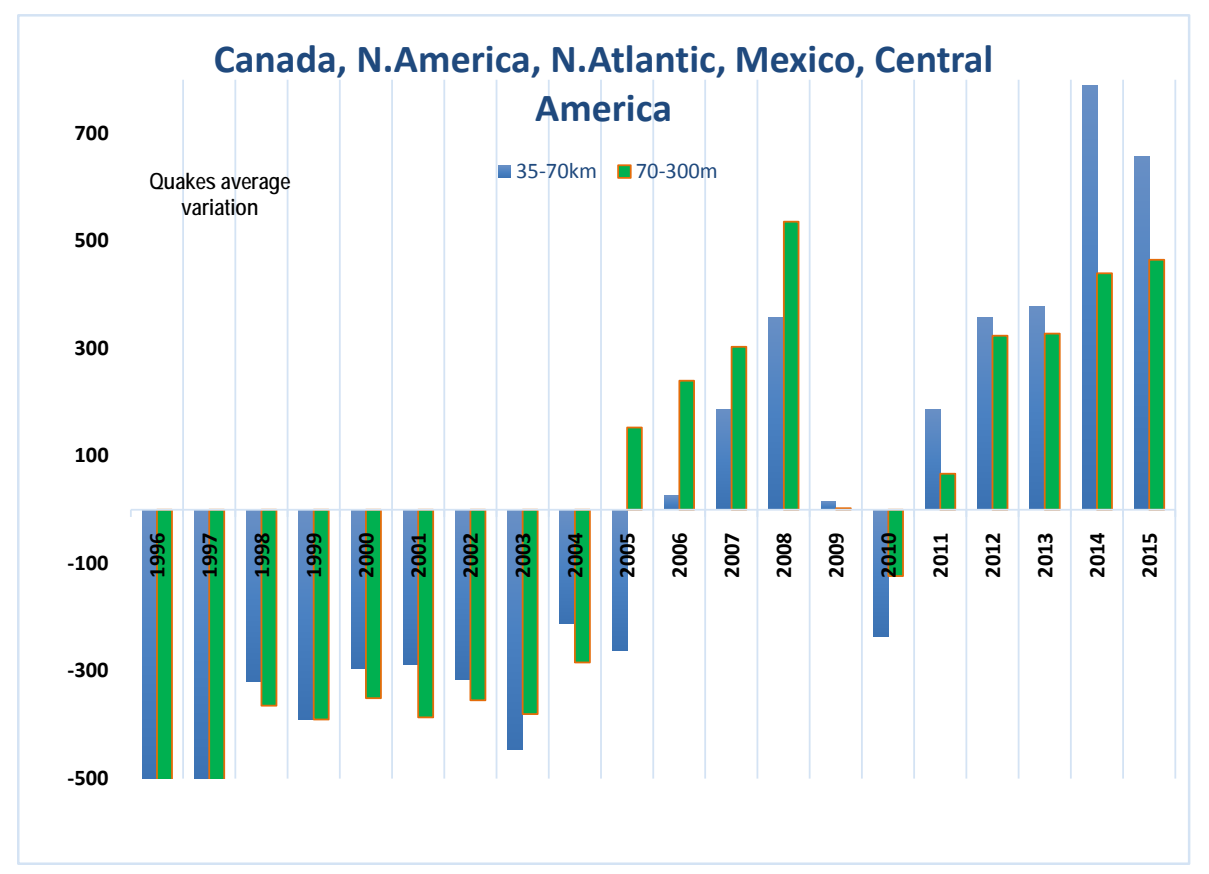

Figure 9. Area D (Canada, N. America, N. Atlantic, Mexico, Central America) shows the variation started to grow in 2005 in the deeper depths of this region and continued until 2008. A short break in 2009-2011, followed by enhancing again in 2011-2014. In 2015, only shallower quakes augmented.

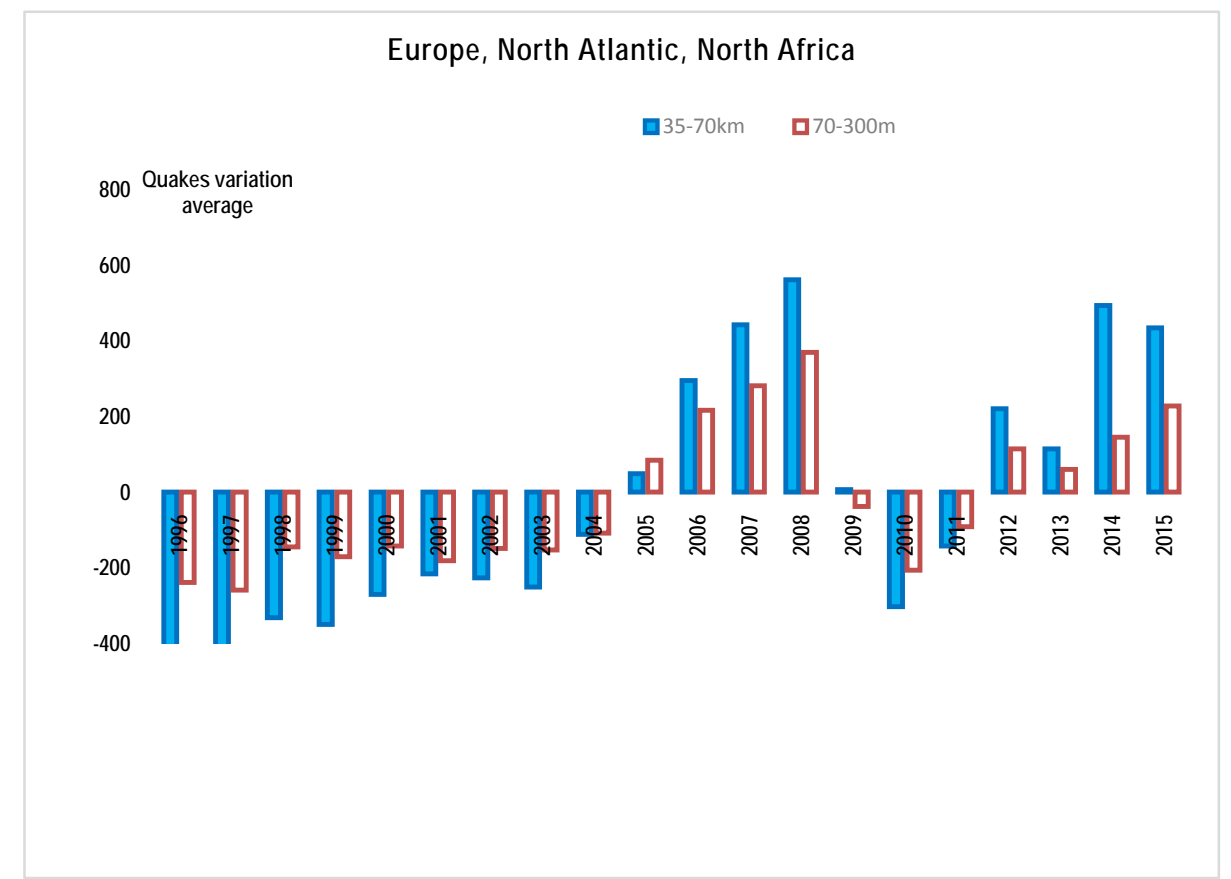

Figure 10. Area E (Europe, North Atlantic, North Africa). The variation in the area is after 2005, mostly at depths of $70-300 \mathrm{~km}$. Both depths showed a sharp increase after 2010.

\subsection{South Atlantic, South Pacific, South Indian, Southern Oceans}

The last two areas in the figures below show earthquakes between $0-35 \mathrm{~km}$. It is necessary to add 
that in 2014 the seismological events increased in G (South Atlantic, South Pacific, Indian Ocean), which coincides with the result shown in Figure 8 where the South Atlantic was calculated as well, Figure 12. This region showed a strong negative growth in 2008. The last area (Southern Ocean) shows a sudden growth in 2013 that differs from previous years, Figure 13. The possible causes are completely unknown and could even be linked to anthropogenic actions in the area in question.

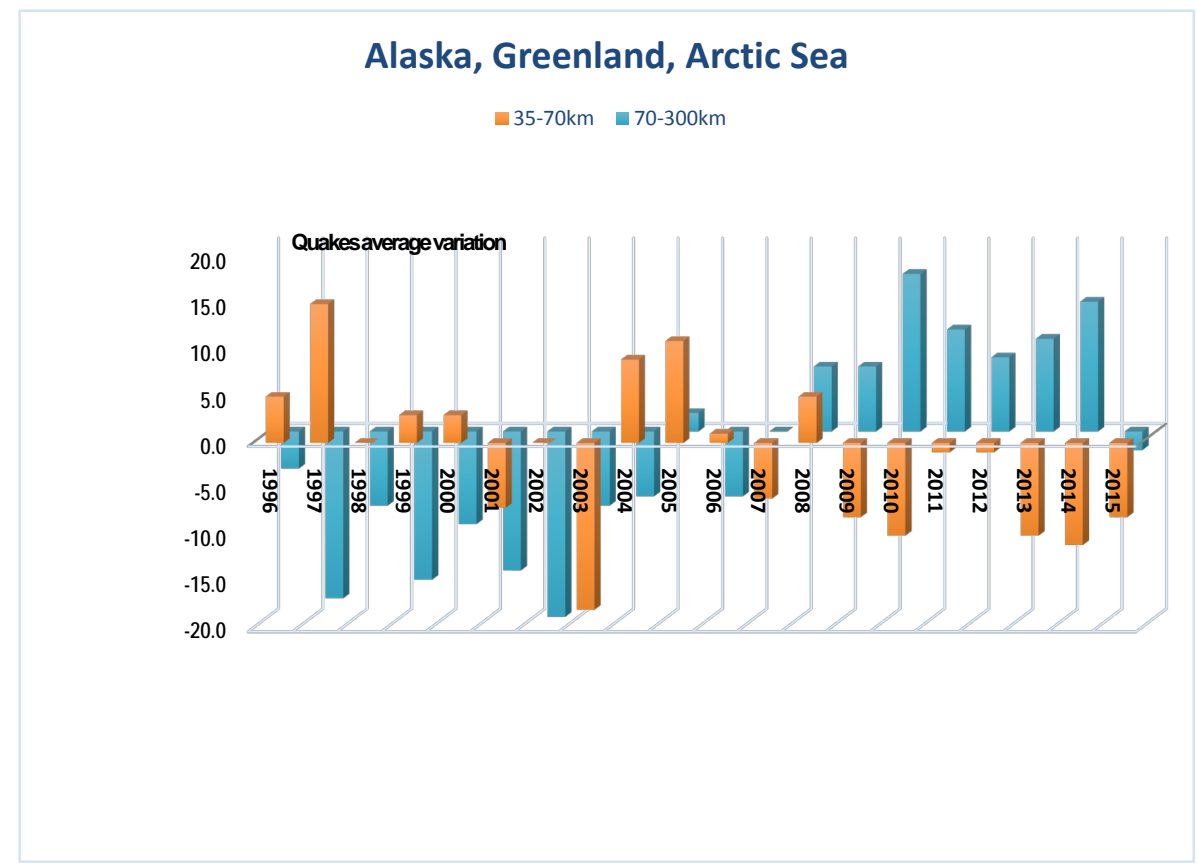

Figure 11. This chart shows an increase of quakes at the highest latitudes of the Earth (Area F-Arctic Sea, Greenland, Northern Atlantic) in $35-70 \mathrm{~km}$ depths in 1996, 1997, 2005, and 2008. The deepest quakes increased 2008-2014 and suddenly decreased in 2015.

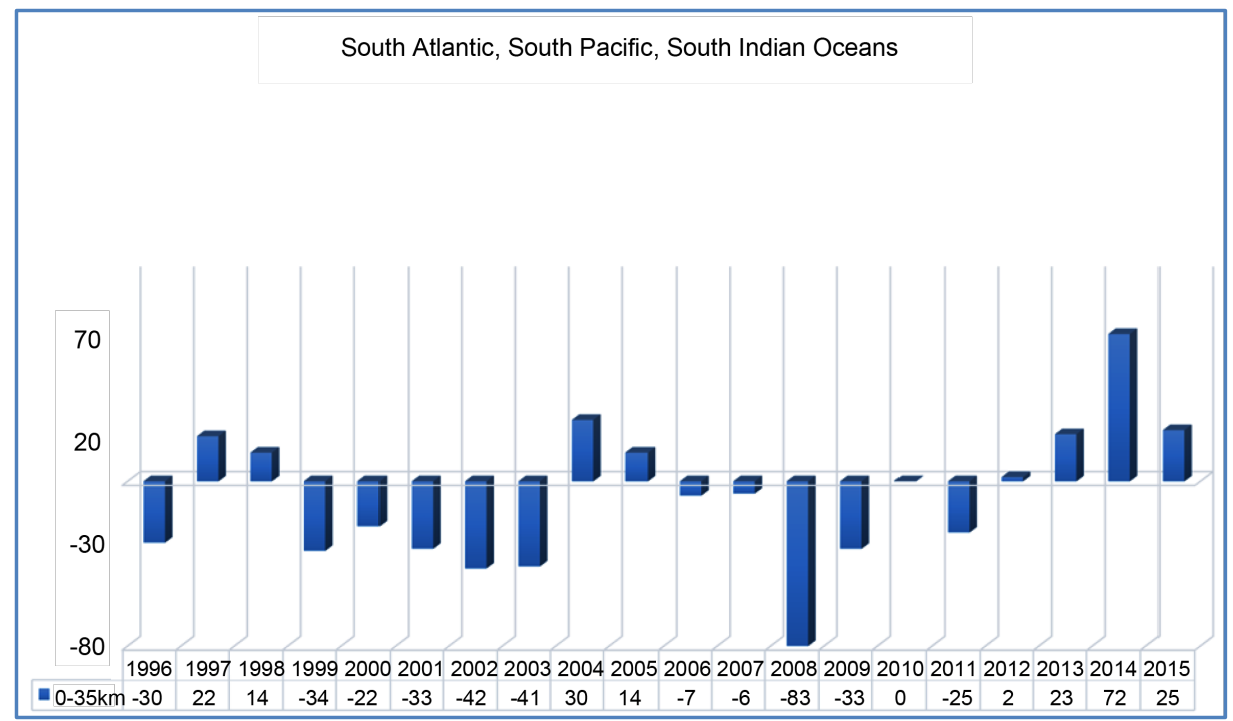

Figure 12. Quakes variation in area G (South Atlantic, South Pacific, South Indian Ocean). This field only has earthquakes at the $0-35 \mathrm{~km}$ depth. In 2014, the increase of earthquakes was $162 \%$ above normal. The quakes enhancement started in 2001 at the depth $1-14 \mathrm{~km}$. 


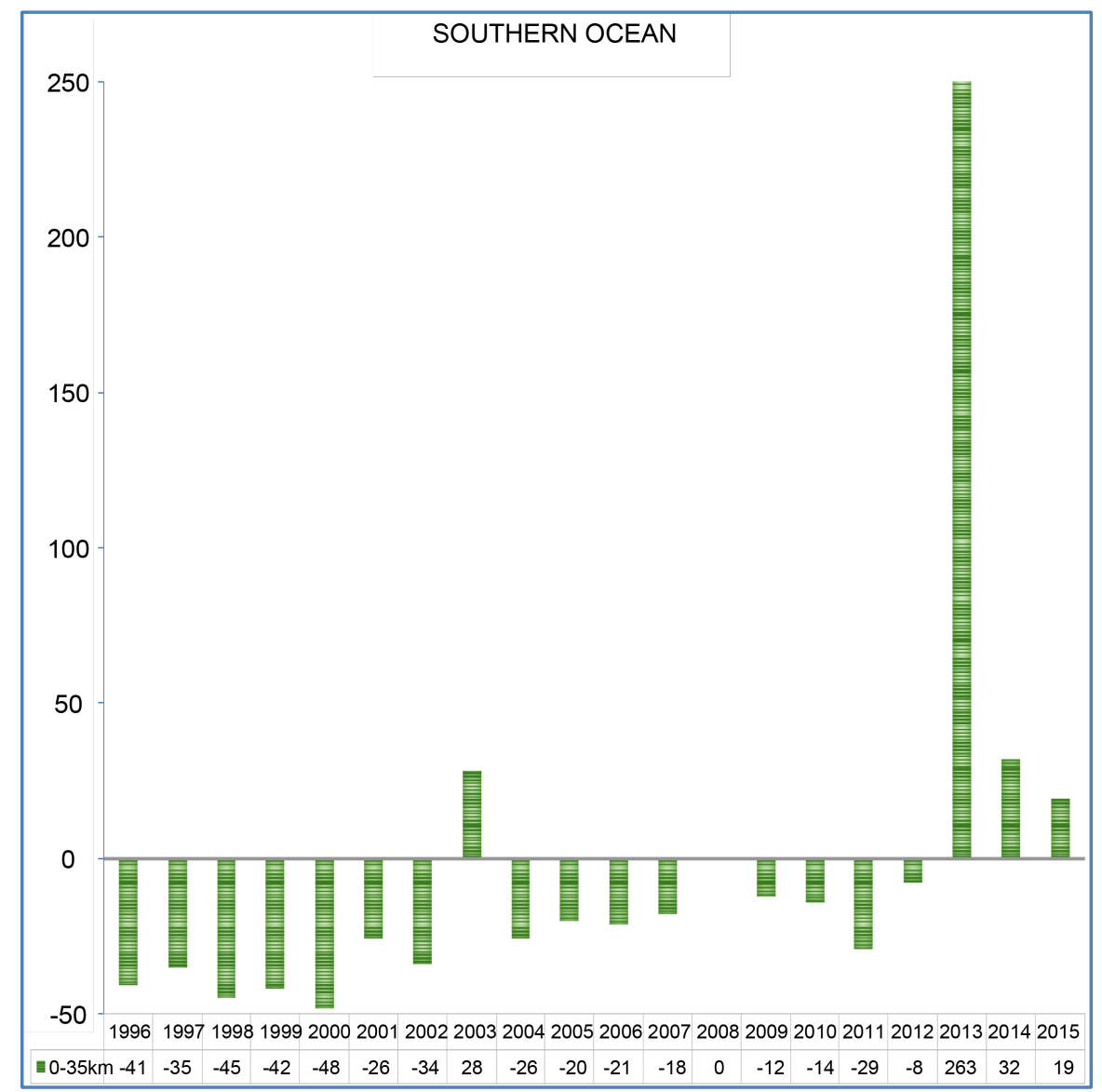

Figure 13. Quakes variation at area $H$. The Southern Ocean presented a real increase in 2003, and 2013-2015. In 2013, unusual activity in the region occurred at the depth $10-20 \mathrm{~km}$. There are no deeper quakes.

\subsection{Solar Cycles-Earth Results}

Our analysis above showed that there was no apparent connection to or reaction from the crust, or inner earth for peak years in the solar cycle such as 2000 or 2014. Behavior of shallower earthquakes in different locations is consistent throughout the entire cycle with small exceptions. This pattern changed when the profundity reached depths of $35-70 \mathrm{~km}$ and $70-300 \mathrm{~km}$. At this depth, some regions showed extreme variation and enhancement of earthquakes that were apparently not connected with the solar maximum. Some locations showed an increase in the years of a minimum, such as 2005-2011. Most locations did not show any enhancement before 2002. The only exception was in the regions of Alaska, Greenland, and the Arctic Sea, which exhibited a sudden increase in 1997 in the $35-70 \mathrm{~km}$ range. In the same year and depth, enhancement happened in the Southern Atlantic, Pacific and Indian oceans. The results at this point are far from the expected and cannot be explained as being linked to the Solar Cycles; other factors must be considered to account for this point.

\section{CONCLUSION}

Our research studied the Sun-Moon-Earth as a three-body system. The first pair, Moon-Earth, showed a gravitational oscillation which is linked with tides and partially affects the geohazard events at subduction zones. The second pair, Sun-Earth, shows an electromagnetic variation interaction between the two bodies, with the Sun having a magnetic field with double the intensity of the Earth's. The statistical 
development in the period 1996-2016 showed inconclusive results for a direct relationship between sunspots maxima and enhancement of earthquakes. However, an intriguing increase of earthquakes during strong geomagnetic storms and deeper shakes will be examined in our future research.

\section{ACKNOWLEDGEMENTS}

Thanks to Paul Killinger for editing and correcting the English on this paper.

\section{REFERENCES}

1. Tavares, M. and Azevedo, A. (2011) Influences of Solar Cycles on Earthquakes. Natural Science, 3.

2. Davidson, B., Kongpop, U.Y. and Holloman, C. (2015) Relationship between M8+ Earthquakes Occurrences and the Solar Polar Magnetic Fields. New Concepts in Global Tectonics Journal, 3.

3. Durham, I.T. Rethinking the History of Solar Wind Studies: Eddington's Analysis of Comet Morehouse. Notes and Records of Royal Society, 60, 261-270.

4. Meyer-Vernet, N. (2007) Basics of the Solar Wind. Cambridge University Press, Cambridge. https://doi.org/10.1017/CBO9780511535765

5. Russel, C.T. (2000) The Solar Wind Interaction with the Earth's Magnetosphere: A Tutorial. Plasma Science, IEEE Transactions.

6. Straser, V. Variations in Gravitational Field, Tidal Force, Electromagnetic Waves and Earthquakes. New Concepts in Global Tectonics Newsletter, 57, 98-2010.

7. Straser, V. and Cataldi, G. (2015) Solar Wind Ionic Variation Associated with Earthquakes Greater than Magnitude 6.0. New Concepts in Global Tectonics Journal, 3.

8. Sibeck, D.G. (1990) A Model for the Transient Magnetosphere Response to Sudden Solar Wind Dynamic Pressure Variations. Journal of Geophysical Research, 95, 3755-3771. https://doi.org/10.1029/JA095iA04p03755

9. Hagen, M. and Azevedo, A. (2016) Gravitation Moon-Earth Forces Triggering Earthquakes in Subduction Zones. Journal of Geography, Environment, and Earth Science International, 8, 1-14. https://doi.org/10.9734/JGEESI/2016/29227

10. Stern, R.J. (2002) Subduction Zones. Reviews of Geophysics, 40. https://doi.org/10.1029/2001rg000108

11. Atakan, K. (2015) On the Origin of Mega-Thrust Earthquakes. In: Ansal, A., Ed., Perspectives on European Earthquake Engineering and Seismology, Springer International, New York. https://doi.org/10.1007/978-3-319-16964-4_19

12. Hapgood, M. (2007) Modelling Long-Term Trends in Lunar Exposure to the Earth's Plasma Sheet. Annales Geophysicae, 25, 2037-2044. https://doi.org/10.5194/angeo-25-2037-2007

13. Yoshiaki, F., Yuki, O., Daisuke, F. and Junichi, K. (2013) Why Do Giant Earthquakes Occur at Lunar Phases Specific to Each Subduction Zone? 6th International Symposium on in-Situ Rock Stress, Sendai, 20-22 August 2013, RS2013-1021.

14. USGS-//earthquake.usgs.gov/earthquakes/recenteqsww/Quakes/quakes_all.php

15. IRIS. http://ds.iris.edu/wilber3/find_event

16. NGDC/NOAA. http://www.ngdc.noaa.gov/hazard/

17. Espenak, F. (2014) Six Millennium Catalog of Phases of the Moon. astropixels.com/ephemeris/phasescat/phasescat.html

18. http://www.moongiant.com/moonphases/october/november/2010/

19. https://www.fourmilab.ch/earthview/pacalc.html (perigee/apogee) 
20. http://solarscience.msfc.nasa.gov/greenwch.shtml

21. http://www.spaceweatherlive.com/solar-activity/top-50-solar-flares/year/2000(-2015)

22. http://services.swpc.noaa.gov/images/solar-cycle-sunspot-number.gif

23. Earthquakes. Historical Earthquakes. http://www.ngdc.noaa.gov/hazard/

24. Earthquakes. http://earthquake.usgs.gov/earthquakes/search/

25. http://www.swpc.noaa.gov/products/solar-cycle-progression

26. http://hvo.wr.usgs.gov/howwork/entrytemp/main.html 


\section{APPENDIX A}

The table shows larger earthquakes recorded since 869 in Japan. Most earthquakes were recorded around the Pacific Ocean. The 1755 Lisbon earthquake is one of the exceptions. They are ordered by largest Magnitudes.

\begin{tabular}{|c|c|c|c|}
\hline Date & Location & Magnitude & Moon Phase \\
\hline $22 / 5 / 1960$ & Chile & 9.5 & New \\
\hline $27 / 3 / 1964$ & Alaska & 9.2 & Full \\
\hline $26 / 12 / 2004$ & Indonesia & 9.3 & Full \\
\hline $11 / 3 / 2011$ & Japan & 9 & $1^{\text {st }} \mathrm{Q}$ \\
\hline 04/11/1952 & Kamchatka & 9 & $1^{\text {st }} \mathrm{Q}$ \\
\hline $13 / 8 / 1868$ & Chile & 9 & $3^{\text {rd }} \mathrm{Q}$ \\
\hline $26 / 1 / 1700$ & Canada & 9 & $1^{\text {st }} \mathrm{Q}$ \\
\hline $9 / 7 / 869$ & Japan & 9 & New \\
\hline $2 / 12 / 1611$ & Japan & 8.9 & New \\
\hline $2 / 4 / 1762$ & Bangladesh & 8.8 & $1^{\text {st }} \mathrm{Q}$ \\
\hline $25 / 11 / 1833$ & Sumatra & 8.8 & Full \\
\hline $31 / 1 / 1906$ & Colombia & 8.8 & $1^{\text {st }} \mathrm{Q}$ \\
\hline $27 / 2 / 2010$ & Chile & 8.8 & Full \\
\hline $15 / 08 / 1950$ & China & 8.7 & New \\
\hline $28 / 9 / 1707$ & Japan & 8.7 & New \\
\hline $8 / 7 / 1730$ & Chile & 8.7 & $3^{\text {rd }} \mathrm{Q}$ \\
\hline $1 / 11 / 1755$ & Lisbon & 8.7 & New \\
\hline $4 / 2 / 1965$ & Alaska & 8.7 & New \\
\hline $28 / 10 / 1746$ & Peru & 8.7 & Full \\
\hline $28 / 03 / 1787$ & Mexico & 8.6 & $1^{\text {st }} \mathrm{Q}$ \\
\hline $28 / 3 / 1787$ & Alaska & 8.6 & New \\
\hline $28 / 3 / 2005$ & Indonesia & 8.6 & Full \\
\hline $11 / 4 / 2012$ & Indonesia & 8.6 & $3^{\text {rd }} \mathrm{Q}$ \\
\hline $16 / 12 / 1575$ & Chile & 8.6 & Full \\
\hline $24 / 11 / 1604$ & Chile & 8.6 & New \\
\hline $13 / 05 / 1647$ & Chile & 8.6 & $1^{\text {st }} \mathrm{Q}$ \\
\hline $24 / 05 / 1751$ & Chile & 8.5 & New \\
\hline $9 / 11 / 1822$ & Chile & 8.5 & $1^{\text {st }} \mathrm{Q}$ \\
\hline $20 / 02 / 1835$ & Chile & 8.5 & $3^{\text {rd }} \mathrm{Q}$ \\
\hline $16 / 02 / 1861$ & Indonesia & 8.5 & $1^{\mathrm{st}} \mathrm{Q}$ \\
\hline $9 / 05 / 1877$ & Chile & 8.5 & $3^{\text {rd }} \mathrm{Q}$ \\
\hline $10 / 11 / 1922$ & Chile & 8.5 & $3^{\text {rd }} \mathrm{Q}$ \\
\hline
\end{tabular}




\begin{tabular}{cccc}
\hline $1 / 2 / 1938$ & Banda Sea & 8.5 & New \\
$13 / 10 / 1963$ & Kuril Is & 8.5 & New \\
$12 / 9 / 2007$ & Indonesia & 8.5 & New \\
$20 / 10 / 1687$ & Peru & 8.5 & Full \\
$17 / 10 / 1737$ & Kamchatka & 8.5 & $3^{\text {rd }} \mathrm{Q}$ \\
$3 / 08 / 1361$ & Japan & 8.5 & New \\
$15 / 06 / 1896$ & Japan & 8.5 & New \\
\hline
\end{tabular}

\section{APPENDIX B}

Earthquakes 1950-2015 with $M \geq 8.0$, location, solar activity at the time, and moon phase. Solar activity is classified as minimum (min), moderate (mod), and maximum (max).

\begin{tabular}{|c|c|c|c|c|c|}
\hline Year & Magnitude & Quakes location & Solar activity & Moon & Region Quakes \\
\hline 1950 & 8.6 & China-India & $\min$ & New & Eurasian \\
\hline 1950 & 8.2 & Chile & $\min$ & New & S. Pacific \\
\hline 1952 & 8.1 & Japan & $\min$ & $1^{\text {st }} \mathrm{Q}-$ & N. Pacific \\
\hline 1952 & 8.9 & Russia & $\min$ & $1^{\text {st }} \mathrm{Q}-$ & N. Pacific \\
\hline 1957 & 8.6 & Alaska & $\min$ & $1^{\text {st }} \mathrm{Q}$ & N. Pacific \\
\hline 1957 & 8.1 & Mongolia & $\min$ & Full & Eurasian \\
\hline 1958 & 8.4 & Kuril Is & $\max$ & $3^{\text {rd }} \mathrm{Q}-$ & N. Pacific \\
\hline 1960 & 8 & Japan & $\min$ & $3^{\text {rd }} \mathrm{Q}$ & N. Pacific \\
\hline 1960 & 8.1 & Chile & $\min$ & New & S. Pacific \\
\hline 1960 & 8.6 & Chile & $\min$ & New & S. Pacific \\
\hline 1960 & 9.6 & Chile & $\operatorname{mini}$ & New & S. Pacific \\
\hline 1963 & 8.5 & Kuril Is & $\bmod$ & Full & N. Pacific \\
\hline 1963 & 8.1 & Banda Sea & $\bmod$ & $1^{\text {st }}-\mathrm{Q}$ & S. Pacific \\
\hline 1964 & 9.3 & Alaska & $\min$ & Full & N. Pacific \\
\hline 1965 & 8.2 & Indonesia & $\min$ & $3^{\text {rd }} \mathrm{Q}$ & S Pacific \\
\hline 1965 & 8.7 & Alaska & $\min$ & New & N. Pacific \\
\hline 1966 & 8.1 & Peru & $\bmod$ & $3^{\text {rd }} \mathrm{Q}$ & S. Pacific \\
\hline 1968 & 8.2 & Japan & $\max$ & $3^{\text {rd }} \mathrm{Q}-$ & N. Pacific \\
\hline 1970 & 8 & Colombia & $\min$ & New & S. Pacific \\
\hline 1971 & 8 & New Guinea & $\min$ & $3^{\text {rd }} \mathrm{Q}-$ & S. Pacific \\
\hline 1971 & 8.1 & New Guinea & $\min$ & $1^{\text {st }} \mathrm{Q}$ & S. Pacific \\
\hline 1972 & 8 & Philippines & $\min$ & New & N. Pacific \\
\hline 1976 & 8 & Kermadec & $\min$ & Full & S. Pacific \\
\hline 1985 & 8 & Chile & $\min$ & Full & S. Pacific \\
\hline 1985 & 8 & Mexico & $\min$ & $1^{\text {st }} \mathrm{Q}-$ & N. Pacific \\
\hline
\end{tabular}




\section{Continued}

\begin{tabular}{|c|c|c|c|c|c|}
\hline 1986 & 8 & Alaska & $\min$ & New & N. Pacific \\
\hline 1989 & 8.2 & Macquarie Is & $\max$ & Full & S. Pacific \\
\hline 1994 & 8.2 & Bolivia & $\min$ & New & S. Pacific \\
\hline 1994 & 8.3 & Kuril Is & $\min$ & New & N. Pacific \\
\hline 1995 & 8 & Chile & $\min$ & New & S. Pacific \\
\hline 1995 & 8 & Mexico & $\min$ & Full & N. Pacific \\
\hline 1996 & 8.2 & Indonesia & $\bmod$ & $3^{\text {rd }} \mathrm{Q}-$ & S. Pacific \\
\hline 1998 & 8.1 & Balleny Is & $\bmod$ & New & S. Pacific \\
\hline 2000 & 8 & New Guinea & $\max$ & $3^{\text {rd }} \mathrm{Q}-$ & S. Pacific \\
\hline 2001 & 8.4 & Peru & $\bmod$ & $1^{\text {st }} \mathrm{Q}-$ & S. Pacific \\
\hline 2003 & 8.3 & Japan & $\bmod$ & New & N. Pacific \\
\hline 2004 & 8.1 & Macquarie Is & $\min$ & Full & S. Pacific \\
\hline 2004 & 9.1 & Sumatra & $\min$ & Full & S. Pacific \\
\hline 2005 & 8.6 & Indonesia & $\min$ & Full & S. Pacific \\
\hline 2006 & 8 & Tonga & $\min$ & $3^{\text {rd }} \mathrm{Q}-$ & S. Pacific \\
\hline 2006 & 8.3 & Kuril Is & $\min$ & Full & N. Pacific \\
\hline 2007 & 8.1 & Kuril Is & $\min$ & $3^{\text {rd }} \mathrm{Q}-$ & N. Pacific \\
\hline 2007 & 8.1 & Solomon Is & $\min$ & Full & S. Pacific \\
\hline 2007 & 8 & Peru & $\min$ & New & S. Pacific \\
\hline 2007 & 8.5 & Indonesia & $\min$ & New & S. Pacific \\
\hline 2009 & 8.1 & Samoa Is & $\min$ & $1^{\text {st }} \mathrm{Q}$ & S. Pacific \\
\hline 2010 & 8.8 & Chile & $\min$ & Full & S. Pacific \\
\hline 2011 & 9 & Japan & $\min$ & $1^{\text {st }} \mathrm{Q}-$ & N. Pacific \\
\hline 2012 & 8.6 & Sumatra & $\min$ & $3^{\text {rd }} \mathrm{Q}-$ & S. Pacific \\
\hline 2012 & 8.2 & Sumatra & $\min$ & $3^{\text {rd }} \mathrm{Q}-$ & S. Pacific \\
\hline 2013 & 8 & Solomon Is & $\min$ & New & S. Pacific \\
\hline 2013 & 8.3 & Okhotsk & $\min$ & Full & N. Pacific \\
\hline 2014 & 8.2 & Chile & $\max$ & New & S. Pacific \\
\hline 2015 & 8.3 & Chile & $\min$ & New & S Pacific \\
\hline
\end{tabular}


Submit or recommend next manuscript to SCIRP and we will provide best service for you:

Accepting pre-submission inquiries through Email, Facebook, LinkedIn, Twitter, etc.

A wide selection of journals (inclusive of 9 subjects, more than 200 journals)

Providing 24-hour high-quality service

User-friendly online submission system

Fair and swift peer-review system

Efficient typesetting and proofreading procedure

Display of the result of downloads and visits, as well as the number of cited articles

Maximum dissemination of your research work

Submit your manuscript at: http://papersubmission.scirp.org/

Or contact ns@scirp.org 